\title{
The Investigation of Crack's Parameters on the V-Notch Using Photoelasticity Method
}

\author{
M. Saravani ${ }^{1}$ and M. Azizi ${ }^{2}$ \\ ${ }^{1}$ Fatigue and Fracture Research Laboratory, School of Mechanical Engineering, Iran University of Science \& Technology, \\ 16846-13114 Tehran, Iran \\ ${ }^{2}$ Wroclaw University of Technology, 50-370 Wroclaw, Poland
}

Correspondence should be addressed to M. Saravani, saravani.m@gmail.com

Received 13 January 2011; Accepted 8 March 2011

Academic Editor: X. Yang

Copyright ( $) 2011$ M. Saravani and M. Azizi. This is an open access article distributed under the Creative Commons Attribution License, which permits unrestricted use, distribution, and reproduction in any medium, provided the original work is properly cited.

V-notches are the most possible case for initiation of cracks in engineering structure. Cracks on the notch tip can be characterized by opening angle, tip radius, and depth of the V-notch. In this study, the effects of V-notch's opening angle on stress intensity factor and on $T$-stress of the crack have been investigated in detail. Our calculation has been performed in a number of opening angles and various crack lengths in mode I loading using photoelasticity method. We show that as opening angle grows at constant crack's length, SIF and T-stress decrease. Furthermore, as the crack's length increases, the V-notch effect diminishes and the crack behavior can be considered as a single-edge crack specimen. Finally, the obtained results were found to be in good agreement with outcome of numerical finite element analysis.

\section{Introduction}

$\mathrm{V}$-notches in engineering structures increase noticeably the risk of failure modes. The evaluation of safe operation of such structures requires a detailed understanding of stresses around the notch tip. V-notch usually acts as a singular stress concentrator, and it has a direct relation with notch angle and notch tip radius. This kind of stress singularity leads to fracture and crack propagation. Therefore, it is important to study the stress singularity and fracture character at the Vnotches tip.

Several investigations have been set to stress intensity coefficient $\left(K_{\mathrm{I}}, K_{\mathrm{II}}\right)$ as well as determination of constant stress parameter $(T)$ in simple geometry bodies under various boundary conditions [1, 2]. However, the experimental methods (i.e., photoelasticity, strain gage, Moiré, and Caustics) are used to determine stress intensity factors $\left(K_{\mathrm{I}}, K_{\mathrm{II}}\right)$ and constant stress $(T)$.

$\mathrm{V}$-notch problem for linear elastic bodies was first investigated by Williams [3]. He described the singular stress field using eigenfunction approach. $T$-stress solution for two- and three-dimensional cracked geometries was analytically investigated by Sherry et al. [1]. Comparing various studies on stress intensity coefficient and second parameter in simple geometries, there are a few works which investigate stress singularity at V-notch. Mahinfalah and Zackery experimentally developed an algorithm to determine mode I and II stress intensity factors of reentrant corners using Williams stress's equation [4]. Kondo et al. analyze the stress intensities of sharp-notched strips utilizing strain gage [5]. Influence of the notch tip radius on the start of the crack was investigated by Leguillon and Yosibash [6]. Yao et al. studied local deformation field and fracture characterization of mode I V-notch tip using coherent gradient sensing (CGS) [7]. Since, the main objective of these studies is effect of Vnotch geometry on crack onset, it seems necessary to research on fracture parameters at $\mathrm{V}$-notch after crack creation. Wang et al. presented a method for estimating $T$-stress in both short and long cracks in notches [8]. This method is used to predict $T$-stress solution for cracks emanating from a Ushaped edge notch in a finite thickness plate.

Herein, photoelasticity method has been employed to study the stress singularity and fracture behavior of cracks at V-notch tip. Experimental and numerical simulation 
for different notch angles and different crack length was performed. The stress intensity factor and $T$-stress of cracks at $\mathrm{V}$-notch tip are obtained in mode I using overdeterministic method. Comparing experimental and numerical results, a fair agreement was recorded.

\section{Application of Photoelastic Method in Fracture Analysis}

Williams [3] illustrated that the stresses for symmetric and antisymmetric fields (mode I and mode II) can be considered as an eigen series expansion. The higher order terms of the series expansion can be negligible around the tip of a crack where $r$ approaches to zero. Hence, stresses, for pure mode I, can be written as the following equations:

$$
\begin{aligned}
& \sigma_{x}=\sum_{n=1}^{\infty} \frac{n}{2} r^{(n-2) / 2}\left\{C _ { 1 n } \left\{\left(2+(-1)^{n}+\frac{n}{2}\right) \cos \left(\frac{n}{2}-1\right) \theta\right.\right. \\
& \left.\left.-\left(\frac{n}{2}-1\right) \cos \left(\frac{n}{2}-3\right) \theta\right\}\right\}, \\
& \sigma_{y}=\sum_{n=1}^{\infty} \frac{n}{2} r^{(n-2) / 2}\left\{C _ { 1 n } \left\{\left(2-(-1)^{n}-\frac{n}{2}\right) \cos \left(\frac{n}{2}-1\right) \theta\right.\right. \\
& \left.\left.+\left(\frac{n}{2}-1\right) \cos \left(\frac{n}{2}-3\right) \theta\right\}\right\}, \\
& \tau_{x y}=\sum_{n=1}^{\infty} \frac{n}{2} r^{(n-2) / 2}\left\{C _ { 1 n } \left\{-\left((-1)^{n}+\frac{n}{2}\right) \sin \left(\frac{n}{2}-1\right) \theta\right.\right. \\
& \left.\left.+\left(\frac{n}{2}-1\right) \sin \left(\frac{n}{2}-3\right) \theta\right\}\right\},
\end{aligned}
$$

And $C_{11} \equiv K_{I} / \sqrt{2 \pi},-4 C_{12} \equiv T$, where $K_{\mathrm{I}}$ is the stress intensity factor of mode I and $r, \theta, x$, and $y$ are coordinates in conventional polar and Cartesian systems, respectively. $T$ is a constant stress parallel to the crack due to a symmetric component of loading.

One of the most popular methods in stress-strain experiments is photoelasticity method. In this method, thick plate of polymer photoelastic material was loaded and isochromatic fringe pattern was stored using image analysis system. The governing equation for two-dimensional models is:

$$
\tau_{m}=\frac{N f_{\sigma}}{2 h}=\frac{\sigma_{1}-\sigma_{2}}{2}
$$

where $\tau_{m}, f_{\sigma}, N$ and $h$ are maximum shear stress, material stress fringe constant, fringe order, and photoelastic model thickness, respectively.

Substituting $N$ from experiment and using $f_{\sigma}$, the maximum shear stress can be determined for each point. The stress intensity coefficients can be extracted using (1) and solving system of equations.

There are many efforts to increase results accuracy including $K_{\mathrm{I}}$ and $T$. All of them use the information of one, two, or three points (fringe order $N$ and position $r$, $\theta)$, and therefore, particular determination of stress intensity coefficients faces many difficulties [9-11]. Dally and Sanford presented a general method to determine $K_{\mathrm{I}}$ and $T$ based on overdeterministic analysis using information of many points near crack tip [12].

According to the overdeterministic method, (2) can be rewritten in following form:

$$
g_{k}\left(C_{1 n}\right)=\left(\frac{\sigma_{y}-\sigma_{x}}{2}\right)_{k}^{2}+\left(\tau_{x y}\right)_{k}^{2}-\left(\frac{N_{k} f_{\sigma}}{2 h}\right)^{2}=0,
$$

where the subscript $k$ indicates the value of $g$ evaluated at the point $\left(r_{k}, \theta_{k}\right)$ with a fringe order $N_{k}$.

Substituting (1) in (3) to calculate the coefficients, one initially makes and estimates the coefficients and computes $g_{k}$ only to find $g_{k} \neq 0$. The initial estimation of $C_{1 n}$ is unreliable. The correction process involves an iterative equation. Based on a Taylor series expansion of $g_{k}$, in order to achieve minimum errors in obtaining $K_{\mathrm{I}}$ and $T$ parameters, the first six terms of (1) were considered in calculation $[13,14]$. In matrix notation (3) becomes

$$
[g]=[C] \cdot[\Delta C]
$$

where

$$
\begin{gathered}
{[g]=\left[\begin{array}{c}
-g_{1} \\
\vdots \\
-g_{k}
\end{array}\right], \quad[C]=\left[\begin{array}{ccc}
\frac{\partial g_{1}}{\partial c_{11}} & \cdots & \frac{\partial g_{1}}{\partial c_{16}} \\
\vdots & \ddots & \vdots \\
\frac{\partial g_{k}}{\partial c_{11}} & \cdots & \frac{\partial g_{k}}{\partial c_{16}}
\end{array}\right],} \\
{[\Delta C]=\left[\begin{array}{c}
\Delta C_{11} \\
\vdots \\
\Delta C_{16}
\end{array}\right] .}
\end{gathered}
$$

The overdetermined system, given in (4), is solved in leastsquares method process. Thus

$$
[\Delta C]=\left([C]^{T}[C]\right)^{-1}[C]^{T}[g] .
$$

The solution of (6) yields correction to be applied to the previous estimates of $C_{1 n}$.

All of the experimental methods to determine stress intensity factors employ data taken from the near field region in Figure 1. Data taken from the very near field do not yield accurate results, because the stress field is three-dimensional (neither plane stress nor plane strain) in this region [15]. Also, if the data points are located very close to the crack tip, errors in measuring $r, \theta$ are often excessive. Since, high number of terms were considered to represent the stress field, data from the far field can be useful too.

\section{Experimental Procedure}

Four specimens of polycarbonate plate (Lexan) with $3 \mathrm{~mm}$ thickness and notch angles $(\alpha) 30^{\circ}, 60^{\circ}, 90^{\circ}$, and $120^{\circ}$ were 




Figure 1: Concept of three regions near a crack tip.

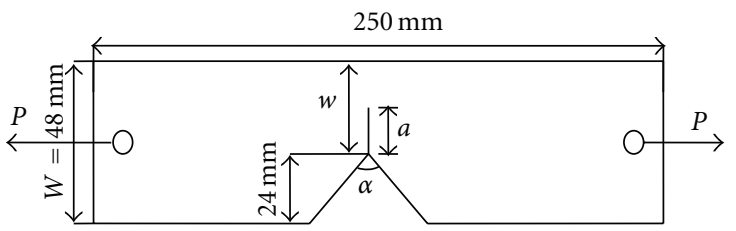

FIGURE 2: Geometry of V-notch photoelastic model.

used for experiment (Figure 2). The mechanical properties of polycarbonate are given in Table 1 [16].

According to (2), $f_{\sigma}$ is the correlation coefficient between optical properties of material and created stress in model. Since photoelastic material properties are changed during the time and these properties can be affected by construction conditions directly, the material stress fringe value should be determined for each experimental material. There are some usual methods to measure the material stress fringe value [17]. In our study, the novel method is presented to estimate this property. An arbitrary geometry was loaded in polariscope to take the photograph of the fringe patterns. The principal stresses of the model $\left(\sigma_{1}, \sigma_{2}\right)$ can be calculated for each point using finite element method. Setting the principal stresses and an initial value of $f_{\sigma}$ in (2), the fringe order $N_{k}$ can be evaluated. Correlating $N$ and the fringe order of photoelastic image, $f_{\sigma}$ can be modified.

Single-edge crack (SEC) specimen (Figure 3) was investigated, and the principal stresses for each point near tip of crack were extracted using finite element model. Principal stresses and every node coordinate were simulated to calculate and compare the fringe order of every node with experimental data. The regeneration fringes for 6.5, 6.8 and $7 \mathrm{kN} / \mathrm{m}$ stress fringe values were compared with the experimental fringe pattern.

One of these comparisons is presented in Figure 4. As it can be seen, the best correlation of the stress fringe value was obtained at $f_{\sigma}=7 \mathrm{kN} / \mathrm{m}$ which is recommended in $[16,17]$. Contrary to usual methods, there is not any geometrical limitation in our procedure and using many points in our evaluation decreases the errors.

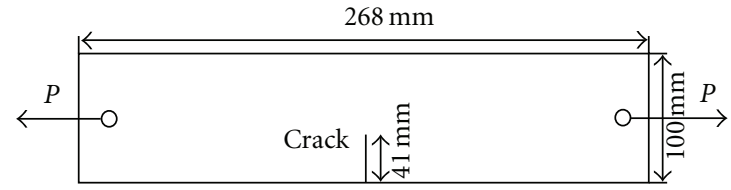

FIGURE 3: Single-edge crack specimen.

TABLE 1: Material properties of polycarbonate.

\begin{tabular}{lllll}
\hline $\begin{array}{l}\text { Sensitivity } \\
\text { index } \\
(1 / \mathrm{mm})\end{array}$ & $\begin{array}{l}\text { Stress } \\
\text { fringe } \\
\text { value } \\
(\mathrm{kN} / \mathrm{m})\end{array}$ & $\begin{array}{l}\text { Yield stress } \\
(\mathrm{MPa})\end{array}$ & $\begin{array}{l}\text { Poisson's } \\
\text { ratio }\end{array}$ & $\begin{array}{l}\text { Module of } \\
\text { elasticity }\end{array}$ \\
\hline 4.92 & 7 & 34.5 & 0.38 & 2480 \\
\hline
\end{tabular}

For empirical test, the crack was produced using special saw with $0.3 \mathrm{~mm}$ thickness. The crack tip was sharply introduced by a fine blade. The plates were loaded in tension in screw-type universal testing machine, and the fringe pattern was displayed in a circular polariscope. The fringe patterns formed around the crack tips were recorded through a monochromatic filter using color digital camera. The fringe patterns were recorded with the polariscope set of both dark and light fields. The isochromatic fringe patterns for different notch angles have been depicted in Figure 5.

We also repeated the experiment for crack length of 0.5 , $1.0,1.5,2.0,3.0$, and $5 \mathrm{~mm}$.

The symmetry of fringe pattern around crack's axis shows the pure mode I loading. The angels corresponding to the maximum radius $\left(\theta_{P}\right)$ were obtained at $\theta_{P} \leq 90^{\circ}$ for all crack's lengthes and notch angles such as Figure 5. According to Ayatollahi and Safari research, it can be concluded that the $T$-stresses are negative for $\theta_{P}<90^{\circ}$ or zero for $\theta_{P}=90^{\circ}$ [18]. In the following, this fact will be approved by the calculation values. The isochromatic fringe patterns were postprocessed with computer code written in MATLAB software. This simulation determines the location and the number of the fringe order. The coordinates and the fringe order $(r, \theta$, and $N$ ) were established for about 80 data points for each photoelastic model. Data was collected from the near field and between the near and far fields.

The full set of data points $(r, \theta$, and $N)$ used as input for MATLAB codes, has been written based on overdeterministic method (6). Although the use of photoelastic data leads to a nonlinear relation between the coefficient of the series expansion of the stresses and the fringe order, the overdeterministic solution converged rapidly. The convergence rate is strongly dependent on the number of data points and the accuracy of selecting them. The calculation converges after 20 iterations (the code accuracy is $\Delta C=10^{-4}$ ), revealing that the employed code is reasonably quick. Comparing analytical solution with those predicted by simulation code using a single-edge crack photoelastic model (Figure 3), a good agreement was recovered. This comparison has been shown in Table 2. 


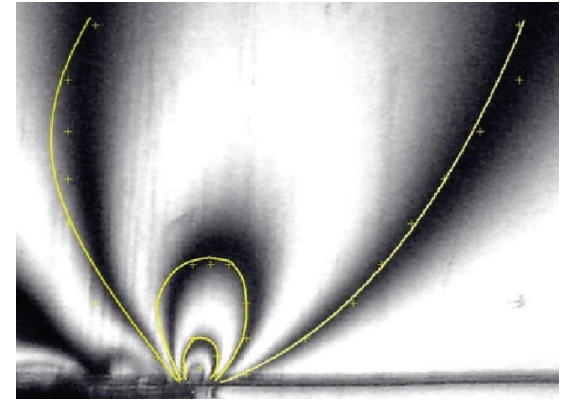

(a)

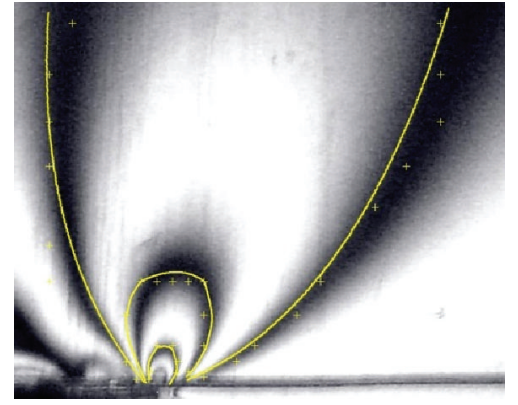

(b)

Figure 4: The simulated original isochromatic fringe pattern for (a) $f_{\sigma}=7 \mathrm{kN} / \mathrm{m}$ and (b) $f_{\sigma}=6.8 \mathrm{kN} / \mathrm{m}$.

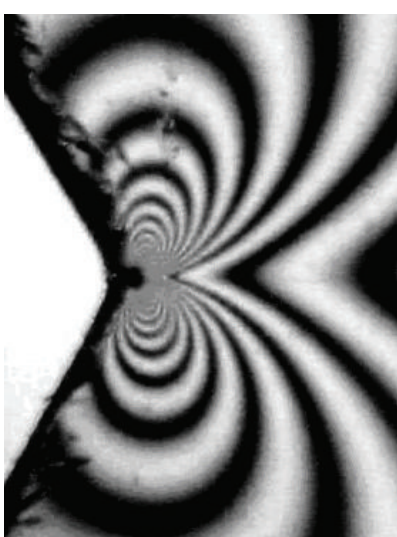

(a)

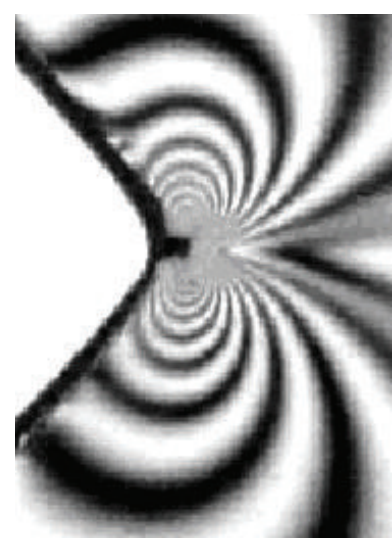

(b)

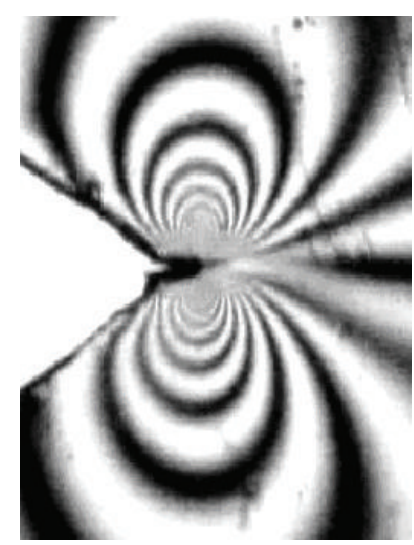

(c)

FIGURE 5: The light field isochromatic fringe patterns around the crack tips for mode I condition: (a) $\alpha=120^{\circ}$; (b) $\alpha=90^{\circ}$; (c) $\alpha=60^{\circ}$.

TABLE 2: The theoretical and experimental results of SEC.

\begin{tabular}{lccc}
\hline Error $\%$ & Theory & Experimental & \\
\hline $7 \%$ & 0.7348 & 0.6827 & $K_{\mathrm{I}}\left(\mathrm{MPa} \cdot \mathrm{m}^{1 / 2}\right)$ \\
$4.6 \%$ & -0.5835 & -0.5565 & $T(\mathrm{MPa})$ \\
\hline
\end{tabular}

\section{Results and Discussion}

Normalized values obtained from four different photoelastic models with various lengths of cracks are presented in Figures 6 and 7, where

$$
\begin{gathered}
K_{\mathrm{I}}(\text { Normalized })=\frac{K_{\mathrm{I}}}{\sigma_{\infty} \sqrt{w}}, \\
T(\text { Normalized })=\frac{T}{\sigma_{\infty}},
\end{gathered}
$$

$a$ is the crack length, $w$ is the specimen width at the notch tip (Figure 2) and $\sigma_{\infty}$ is the constant stress far from the plate.

According to Figures 6 and 7, as crack's length grows in a specimen, the stress intensity factor and $T$-stress increase, and when notch angle increases in constant crack's length,

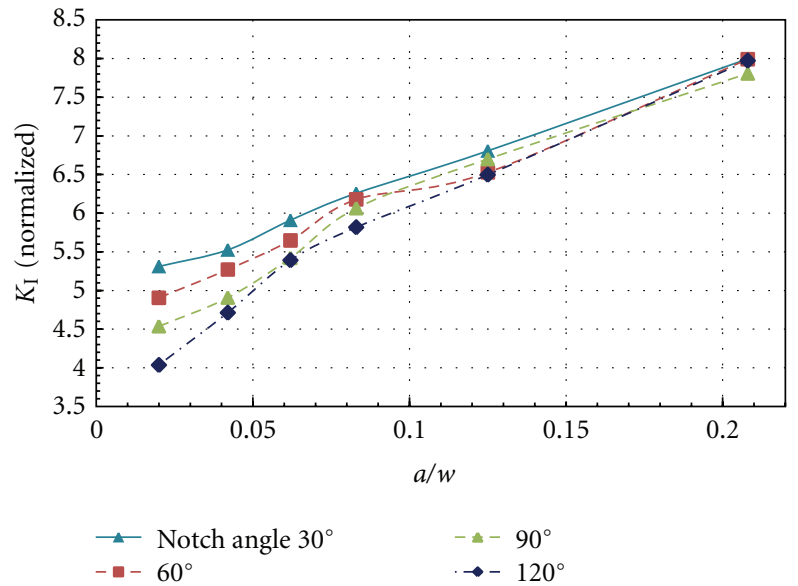

FIGURE 6: The variation of normalized $K_{\mathrm{I}}$ versus $a / w$ in different notch angles from the experiment.

SIF and $T$-stress reduce. As a corollary of the previous prediction, the values of $T$-stress are negative. This result can be justified by decreasing the singularity effect in the root of notch. One can conclude that the crack's growing leads to the notch angle effects decrease on the crack parameter. 


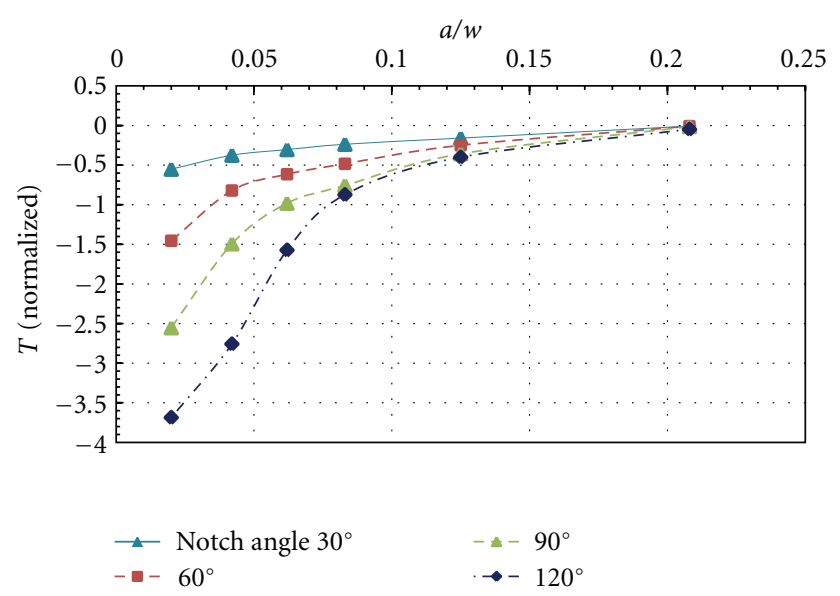

Figure 7: The variation of normalized $T$ versus $a / w$ in different notch angles from experiment.

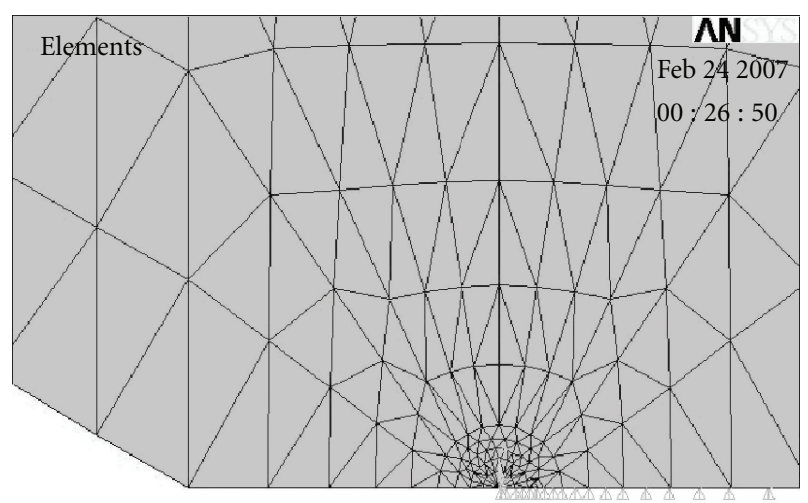

Figure 8: FEM Mesh.

Finite element analysis was performed to compare the experimental results. Since the photoelastic model was symmetrically loaded mode I, the finite element model was considered semisymmetric. Finite element model of plate specimen was illustrated in Figure 8. There is not any geometry limitation to produce crack in FEM, and short crack of 0.1 and $0.3 \mathrm{~mm}$ in length is additionally analyzed in the simulation. The model includes six node triangular plane stress elements. According to Ayatollahi et al.'s report, SIF and $T$-stress were calculated from FE results for the same experimental geometry and the same tension load [19].

The normalized stress intensity factor and $T$-stress in different crack's lengthes for different opening notch angles have been shown in Figures 9 and 10. FEM results are in fair agreement with experimental results.

The difference between experimental and FEM results is due to the finite element ideal modeling, while in the experimental specimen, the existence of V-notch tip radius is unavoidable.

Both experimental and FEM results illustrate that the increase of the crack length results in the decrease of the notch angle effects and for crack length more than 0.125 of specimen width it is negligible.

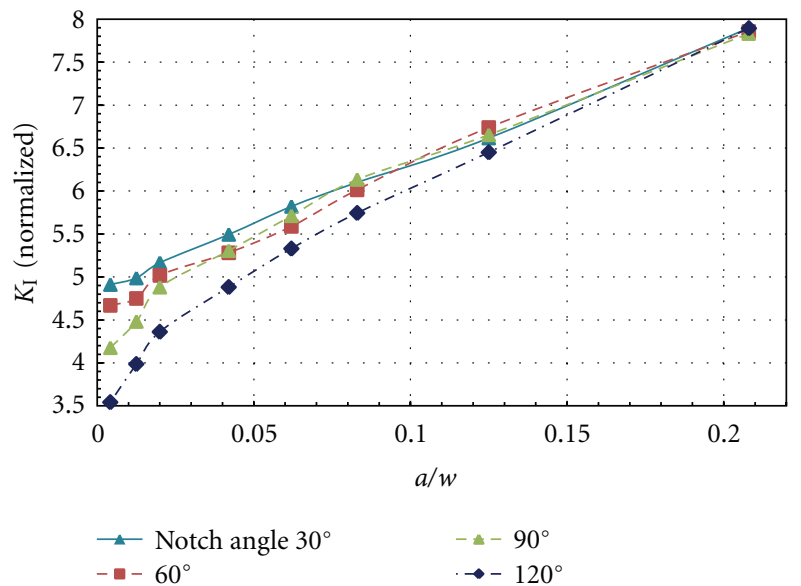

FIGURE 9: The variation of normalized $K_{\mathrm{I}}$ versus $a / w$ in different notch angles from FEM.

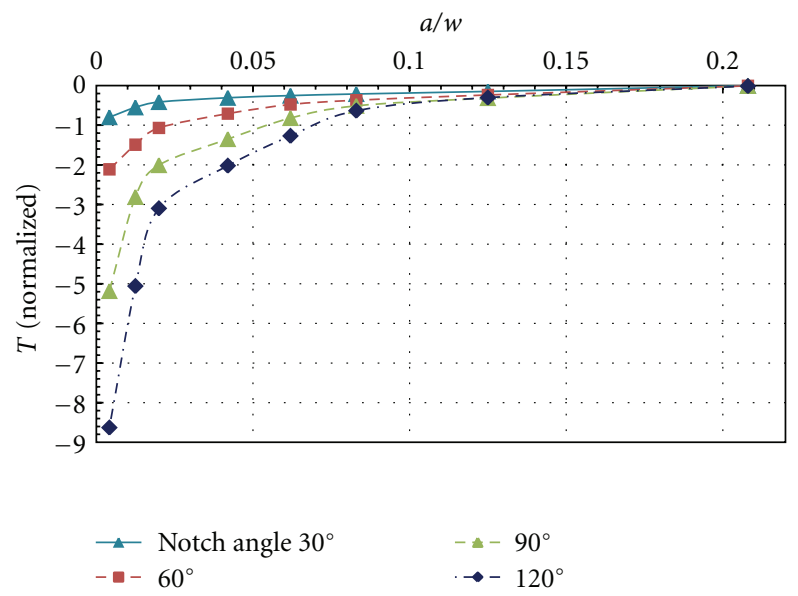

Figure 10: The variation of normalized $T$ versus $a / w$ in different notch angles from FEM.

The experimental results were compared to the results of single-edge crack (notch angle $\alpha=0$ ) as the length of SEC is equal to the summation of depth of notch and the experimental crack length.

To calculate the results of SEC, a theoretical method has been used $[1,20]$.

In V-notch specimen including crack, when the crack's length is the more than 0.125 , the behavior of the crack's growth is similar to single-edge crack specimen.

\section{Conclusion}

(1) We presented a method using the results of photoelastic and finite elements to extract stress fringe value for photoelastic materials. There is a good agreement between our results and handbook's reports.

(2) $K_{\mathrm{I}}$ and $T$-stress were calculated in cracked specimen for different $\mathrm{V}$-notch angles under pure mode I loading using photoelasticity method. 


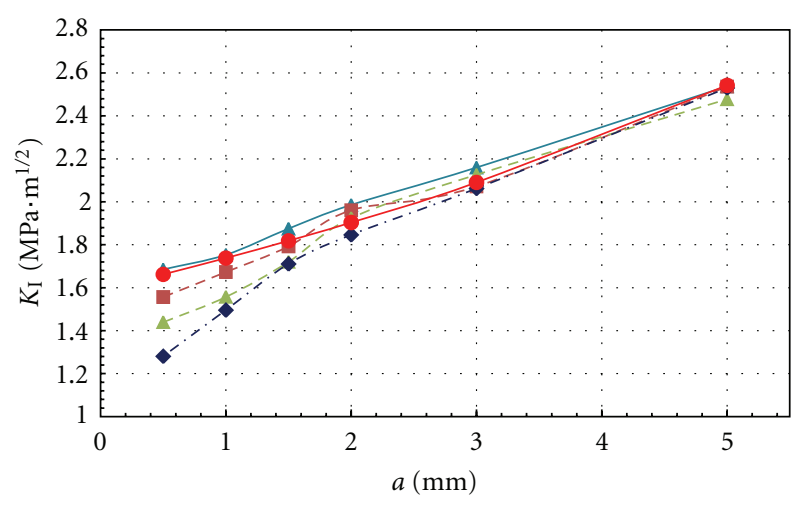

(a)

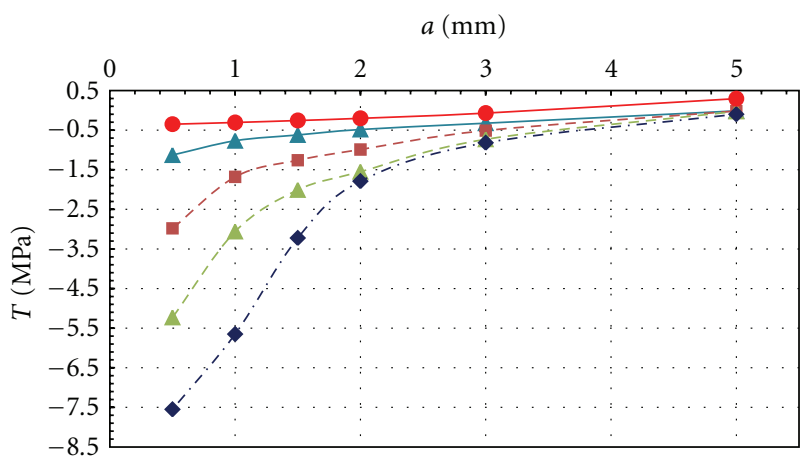

$$
\begin{array}{ll}
\longrightarrow \text { Notch angle } 30^{\circ} & \longrightarrow-120^{\circ} \\
--60^{\circ} & \longrightarrow \text { SEC } \\
-\triangle-90^{\circ} &
\end{array}
$$

FIgURE 11: The comparison of V-notch's experimental results of specimen and SEC: (a) $K_{1}$; (b) $T$-stress.

(3) The results of the photoelasticity method were compared with finite element model, and, a good agreement was obtained.

(4) The experimental and simulation results show that by increasing the length of crack in the V-notch specimen, the value of $K_{\mathrm{I}}$ and $T$-stress will be close to each other in different V-notch angles (Figure 11). For a crack's length more than 0.125 of specimen's width, the notch effect can be negligible and the crack behavior will be similar to the single-edge crack specimen.

\section{References}

[1] A. H. Sherry, C. C. France, and M. R. Goldthorpe, "Compendium of T-stress solutions for two and three dimensional cracked geometries," Fatigue and Fracture of Engineering Materials and Structures, vol. 18, no. 1, pp. 141-155, 1995.

[2] R. Jones, D. Peng, S. Pitt, and C. Wallbrink, "Weight functions, CTOD, and related solutions for cracks at notches," Engineering Failure Analysis, vol. 11, no. 1, pp. 79-114, 2004.

[3] M. L. Williams, "Stress singularities resulting from various boundary conditions insingular corners of plates inextension," Journal of Applied Mechanics, vol. 19, no. 3, pp. 526-528, 1952.
[4] M. Mahinfalah and L. Zackery, "Photoelastic determination of mixed mode stress intensity factors for sharp reentrant corners," Engineering Fracture Mechanics, vol. 52, no. 4, pp. 639-645, 1995.

[5] T. Kondo, M. Kobayashi, and H. Sekine, "Strain gage method for determining stress intensities of sharp-notched strips," Experimental Mechanics, vol. 41, no. 1, pp. 1-7, 2001.

[6] D. Leguillon and Z. Yosibash, "Crack onset at a v-notch. Influence of the notch tip radius," International Journal of Fracture, vol. 122, no. 1-2, pp. 1-21, 2003.

[7] X. F. Yao, H. Y. Yeh, and W. Xu, "Fracture investigation at V-notch tip using coherent gradient sensing (CGS)," International Journal of Solids and Structures, vol. 43, no. 5, pp. 1189-1200, 2006.

[8] X. Wang, T. Lewis, and R. Bell, "Estimations of the T-stress for small cracks at notches," Engineering Fracture Mechanics, vol. 73, no. 3, pp. 366-375, 2006.

[9] D. G. Smith, "Photoelastic determination of mixed mode stress intensity factors," Engineering Fracture Mechanics, vol. 4, no. 2, pp. 357-366, 1972.

[10] E. E. Gdoutos and P. S. Theocaris, "A photoelastic determination of mixed-mode stress-intensity factors," Experimental Mechanics, vol. 18, no. 3, pp. 87-96, 1978.

[11] J. M. Etheridge and J. W. Dally, "A three parameter method of determining SIF from isochromatic fringe loops," Journal of Strain Analysis for Engineering Design, vol. 13, no. 2, pp. 91-94, 1978.

[12] J. W. Dally and R. J. Sanford, "A general method for determining mixed-mode stress intensity factors from isochromatic fringe patterns," Engineering Fracture Mechanics, vol. 11, no. 4, pp. 621-633, 1979.

[13] K. Ramesh, S. Gupta, and A. A. Kelkar, "Evaluation of stress field parameters in fracture mechanics by photoelasticity," Engineering Fracture Mechanics, vol. 56, no. 1, pp. 25-45, 1997.

[14] R. K. L. Su and W. J. Feng, "Accurate determination of mode I and II leading coefficients of the Williams expansion by finite element analysis," Finite Elements in Analysis and Design, vol. 41, no. 11-12, pp. 1175-1186, 2005.

[15] J. W. Dally and R. J. Sanford, "Experimental determination of $\mathrm{K}_{I}$ for short internal cracks," ASME Journal of Applied Mechanics, Transactions, vol. 68, no. 6, pp. 937-943, 2001.

[16] J. W. Dally and W. F. Riley, Experimental Stress Analysis, MC Graw-Hill, 3rd edition, 1991.

[17] K. Ramesh, Digital Photoelasticity, Springer, 2nd edition, 2000.

[18] M. R. Ayatollahi and H. Safari, "Evaluation of crack tip constraint using photoelasticity," International Journal of Pressure Vessels and Piping, vol. 80, no. 9, pp. 665-670, 2003.

[19] M. R. Ayatollahi, M. J. Pavier, and D. J. Smith, "Determination of T -stress from finite element analysis for mode I and mixed mode I/II loading," International Journal of Fracture, vol. 91, no. 3, pp. 283-298, 1998.

[20] T. L. Anderson, Fracture Mechanics Fundamental and Applications, CRC Press, 2nd edition, 1995. 

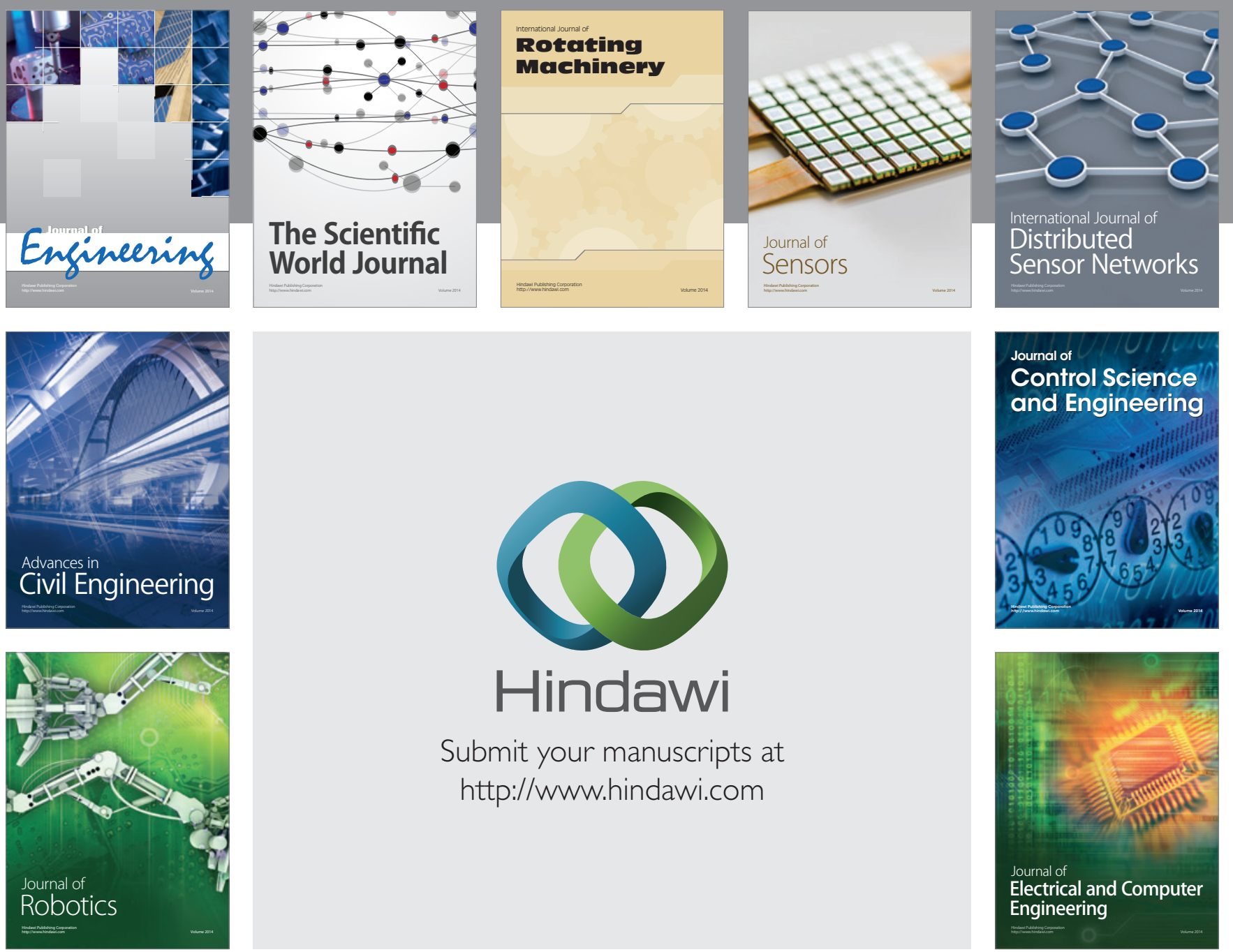

Submit your manuscripts at

http://www.hindawi.com
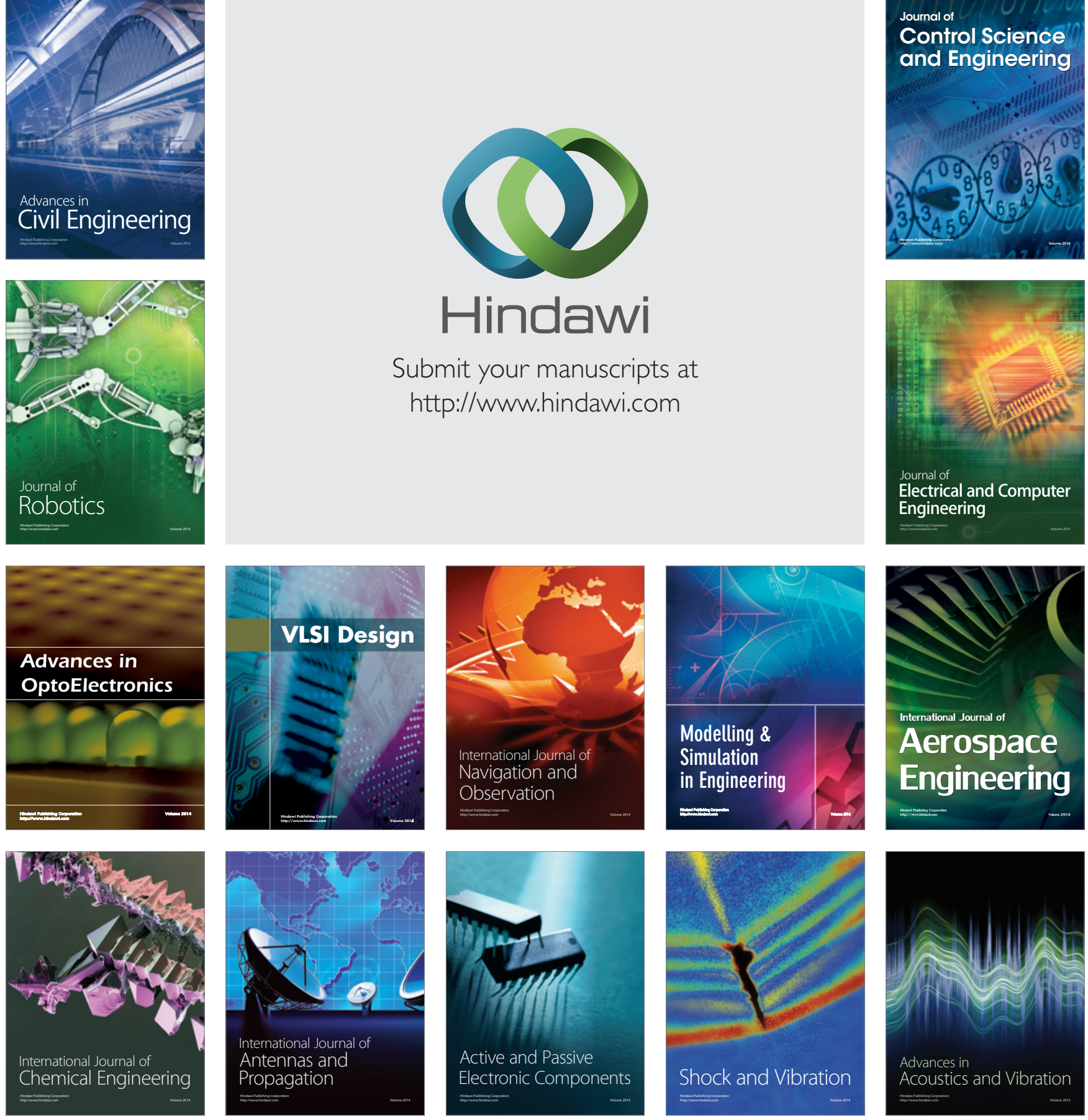